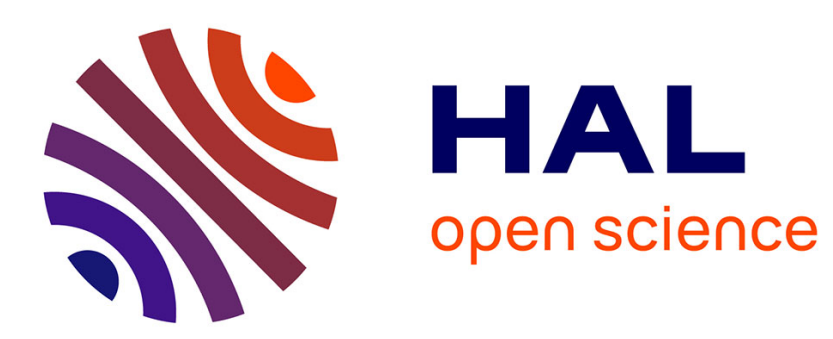

\title{
Implicit internal arguments, event structure, predication and anaphoric reference
}

Francis Cornish

\section{To cite this version:}

Francis Cornish. Implicit internal arguments, event structure, predication and anaphoric reference. N. Hedberg \& R. Zacharski. The Grammar-Pragmatics Interface. Essays in honor of Jeanette K. Gundel, John Benjamins, pp.189-216, 2007. hal-00967905

\section{HAL Id: hal-00967905 \\ https://hal-univ-tlse2.archives-ouvertes.fr/hal-00967905}

Submitted on 31 Mar 2014

HAL is a multi-disciplinary open access archive for the deposit and dissemination of scientific research documents, whether they are published or not. The documents may come from teaching and research institutions in France or abroad, or from public or private research centers.
L'archive ouverte pluridisciplinaire HAL, est destinée au dépôt et à la diffusion de documents scientifiques de niveau recherche, publiés ou non, émanant des établissements d'enseignement et de recherche français ou étrangers, des laboratoires publics ou privés. 
Published as Chapter 9 in Hedberg, N. \& Zacharski, R. (eds.) (2007), The Grammar-Pragmatics Interface. Essays in Honor of Jeanettte K. Gundel. Amsterdam \& Philadelphia: John Benjamins (Pragmatics and Beyond series), pp. 189-216.

\title{
IMPLICIT INTERNAL ARGUMENTS, EVENT STRUCTURE, PREDICATION AND ANAPHORIC REFERENCE ${ }^{1}$
}

Francis Cornish,

ERSS UMR 5610 \& Département d'Etudes du Monde Anglophone (Studies of the

Anglophone World department),

Université de Toulouse-Le Mirail,

5, Allée Antonio Machado,

31058 Toulouse Cedex 09, France.

<cornish@univ-tlse2.fr>

\begin{abstract}
This chapter deals with zero or implicit internal arguments of predicates which may take one or two internal arguments, realizable syntactically. It begins by distinguishing implicit (internal) arguments in terms of a predicate's semantic valency in relation to the syntactic valency of the verb or adjective corresponding to that predicate $(\$ 2)$, and continues with an attempt to distinguish three semantic or discourse-referential values assumable by null complements $(\S 3)$. Section 4 then examines one of the three sub-types of null complement isolated in $\S 3$ (the contextually-definite anaphoric subtype), in an attempt to make precise its anaphoric potential, as compared with that of unaccented $3^{\text {rd }}$ person personal pronouns. It is shown that this is a function of an interaction amongst the event-type designated by the clause as a whole, the host predicate's selection restrictions, the choice of zero vs. overt pronoun as complement, and wider contextual factors. Finally, section 5 examines the role of the host predication as a whole in the functioning of non-referential and anaphoric null complements, and attempts to arrive at certain generalisations licensing the possible occurrence of null complements bearing the three types of values isolated.
\end{abstract}

\section{Introduction}

This chapter deals with zero or implicit internal arguments of predicates which may take one or two internal arguments, realizable syntactically. There are three essential issues concerning the possibility of occurrence and the type of interpretation of null complements.

First, what are the conditions under which they may occur with various types of transitive verbs?

Second, what are the semantic and referential values which these null complements may assume in different contexts?

\footnotetext{
${ }^{1}$ I am very grateful to Christopher Butler, Anne Grobet, Daniel García Velasco, Denis Apothéloz, Michelle Noailly, Nancy Hedberg, Ron Zacharschi, Ricardo Mairal Usón, an initial anonymous external reviewer and two anonymous John Benjamins' reviewers for their careful reading of earlier drafts of this chapter. A formalized version of this chapter, framed within the context of K. Hengeveld's Functional Discourse Grammar model, was presented at the Seminar on Functional Discourse Grammar within the $7^{\text {th }}$ International Conference of the European Society for the Study of English, at the University of Saragossa, Spain, on $9^{\text {th }}$ September, 2004. The title of this paper was "Null complements, event structure, predication and anaphora: a Functional Discourse Grammar account". Responsibility for the opinions expressed in the present chapter, as well as for any remaining errors, is of course mine alone. A more extended, collaborative project studying the contrast between null complements and overt pronouns in natural spoken discourse in French began in June 2003 with Anne Grobet (University of Geneva).
} 
Third, what are the principles which make these values possible? Clearly, the occurrence of null complements needs to be licensed - it is not just any transitive verb, in any type of context, which may leave its direct and/or indirect complement(s) unrealized syntactically. A satisfactory account of the possibility of non-realisation of one or both of a predicate's internal arguments syntactically, and when this is possible, of the kind of interpretation they may receive, requires recognizing the existence of an interaction amongst lexical-semantic structure, the construction selected as a whole, and various discoursecontextual factors. It is these issues which I will be addressing in what follows.

I will start by distinguishing implicit (non-first) arguments in terms of a predicate's semantic valency in relation to the syntactic valency of the verb or adjective corresponding to that predicate $(\$ 2)$, and will continue with an attempt to distinguish three semantic or discourse-referential values assumable by null complements (§3). A third level needs to be recognised, in terms of discourse, namely that at which a potential discourse referent is evoked, corresponding to the relevant internal argument, and where the entire predication at issue has a contextually-specific value as designating an eventuality of some kind (cf. Berrendonner, 1995: 216). Section 4 then mainly examines one of the three sub-types of null complement isolated in $\S 3$ (the contextually-definite anaphoric subtype), and attempts to make precise its anaphoric potential, as compared with that of unaccented $3^{\text {rd }}$ person personal pronouns. Section 4 also examines in detail the event-structural, and more generally, predicational, values which correlate with the presence of a null complement. Finally, section 5 attempts to arrive at certain generalisations motivating the three types of values isolated.

\section{Semantic vs. syntactic valency and null complements}

A distinction is needed at the outset between two conceptions of the notion "(non-first) argument": on the one hand, non-first arguments of the functor which represents the sense of the predicate concerned within the lexical-semantic structure corresponding to this predicate (such arguments may or may not be realizable syntactically). These are thus semantic arguments; and on the other, non-first arguments of the lexical form of the predicate concerned. These arguments are by definition realizable syntactically in conjunction with the lexical form concerned, and normally correspond to arguments of the functor within the lexical-semantic structure corresponding to the lexical form as potential predicate. They are thus syntactic arguments (cf. also Jackendoff, 2002: 138-149 on this distinction). In the case of Simon Dik's version of Functional Grammar (Dik, 1997), this distinction is not explicitly or consistently drawn or followed (cf. Cornish, 2002: 256-7), though it is made explicit by Van Valin \& LaPolla (1997: 27-8) in their comparable model, Role and Reference Grammar; see also their Table 4.1, p. 147. At the discourse level, "semantic" internal unrealized arguments may or may not evoke a particular discourse referent.

Examples (2) and (3) respectively, illustrate the first two aspects of this three-way distinction.

(1) a John saw the "No Entry" sign.

$\mathrm{b}$ The postman placed the packet in the tray.

c The car hit the railing. 
In the case of the verbs in (1), the syntactically expressed internal arguments apparently cannot be unrealized:

(2) $\mathrm{a}^{\prime} *$ John $\mathrm{saw}^{2}$.

$\mathrm{b}^{\prime} *$ The postman placed.

$\mathrm{c}^{\prime} *$ The car hit.

Note however that, where the predicator see has its "understand" sense, where the internal argument is understood as a propositional content of some kind (a third-order entity), the latter may well be unrealized, given a suitable context:

(2) a' A[Garage mechanic]: Your brake pads are completely worn. I'll have to replace them.

B [Motorist]: I see $\boldsymbol{\theta}$. How much will that cost?

This shows that the possibility or obligatoriness of realizing a given argument is a function of the semantics of a given lexical predicate as well as of the argument concerned (cf. Pustejovsky, 1995), and not of its syntactic status qua lexical item. See also Levin \& Rappaport Hovav (2005: 18) on this point.

However, the 3-place predicate place is somewhat different from the 2-place predicates see and hit, in that it may well occur in context without one of its "internal" arguments being syntactically instantiated. This "locative" $\mathrm{A}^{3}$ internal argument then becomes 'tacit", recoverable from the context of utterance of the clause involved. In this particular case then, we see that the semantic and syntactic valencies of a predicate may diverge - its syntactic valency being reduced to 2 , while its semantic valency remains at 3 . But even transitive verbs like hit may occur in context with only their $\mathrm{A}^{1}$ (first argument) instantiated, as in this attested example from the genre of journalism:

(2) $\mathrm{c}^{\prime \prime} \quad$ [Context: article about a $1.3 \mathrm{~kg}$ meteorite which crashed into a New Zealand couple's living room shortly before breakfast] “...Even at that speed [several hundred metres per second] it would have been

\footnotetext{
${ }^{2}$ This is clearly highly language-specific, since the equivalent verb in other languages may well leave its internal argument unexpressed syntactically, even under a specific, anaphoric interpretation of the zero form. Huang (2000: 78) gives the following example from European Portuguese:
}

(i) José sabe que Maria фviu. José knows that Maria saw

'José knows that Maria saw (him)'

(Example (2.130a) in Huang, 2000)

In familiar spoken French, non-realization of the internal argument of the equivalent verb voir could not occur anaphorically in this tightly-integrated environment (within a complement clause). However, it could well occur as such in a syntactically less integrated context:

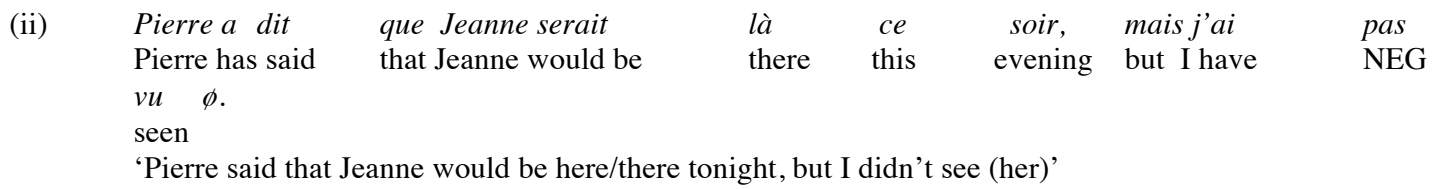


moving fast enough to kill on the spot and the Archers' one-year-old grandson had been playing in the room moments before it hit." (The Guardian, 14.06 .04 , p. 2)

Note here that the inanimate pronoun it would not be appropriate as a substitute for the null complement of hit in this example (it would tend to be interpreted as referring back to "the room in which the Archers' one-year-old grandson had been playing').

\section{(3) a Mike sawed, and Mildred pruned. \\ b Mary is pregnant. \\ c Hilda read, while Jim wrote.}

In (3), by contrast, one or more non-first argument(s) of the predicator have not been realized (these are the "cognate" or the highly expected arguments of the verb in each case): the object sawed (typically a log or plank) and the instrument of the sawing, prototypically 'a saw' in (3a), 'the baby' with which Mary is pregnant in (3b), and 'reading matter' and 'written matter' (the product of the act of writing) in (3c). The verbs in (3a) and (3c) are all "incrementalobject" verbs (see Van Hout, 1999). But it would be a mistake to believe that these predicates' $\mathrm{A}^{2}$ in their transitive use has disappeared at the lexical-semantic level when they are not realized syntactically, since it is quite possible for the interlocutor to question this entity: ...I wonder what Ron sawed/Mildred pruned? for (3a), and ...I wonder what Hilda read/Jim wrote? in (3c) (cf. Fillmore's, 1986 test).

Clearly in these cases, the non-instantiation of the $\mathrm{A}^{2}$ has had the effect of turning an accomplishment predication (where all the predicates' arguments are lexically instantiated) into an activity one (where their non-instantiated $\mathrm{A}^{2}$ arguments are construed as indeterminate or generic: see $\$ 3.1$ below for definitions of these terms). It is by hypothesis the highly specific selection restriction imposed on the instantiation of this argument position which is responsible for transferring this semantic property to the non-instantiated argument positions ${ }^{3}$. This results in the understanding that, for example, "Ron sawed logs" and "Mildred pruned roses" in an utterance of (3a), and that "Hilda read books/magazines/newspapers" and "Jim wrote letters/his diary/articles" in one of (3c) (the context of utterance is clearly responsible for delimiting the specific understanding of these null $\mathrm{A}^{2 \text {, }} \mathrm{s}$ in such instances). In each case, though with the exception of the first internal argument in (3a), oddity would arise if this unexpressed argument were to be realized without modification of some kind or other:

(2) a' ?Mike sawed the log with a saw.

b' ?Mary is pregnant with a baby/child.

$\mathrm{c}^{\prime}$ ?Hilda read reading matter, while Jim wrote written matter.

This would not be the case, however, if the cognate argument were modified in its syntactic realization (cf. Pustejovsky's 1995: 63-7 notion of "shadow argument"). Clearly, such shadow "cognate" or highly expected arguments form part of the lexical-semantic structure of the predicates concerned, and as such correspond to what Mairal Usón \& Faber (2002) call "internal variables" (cf. also Van Valin \& LaPolla, 1997: 117-118) — aspects of the meaning

3 Cf. Dik’s (1997a : §4.2.6) account of the operation of selection restrictions within standard FG. 
of a predicate which characterize the general lexical class of predicates of which it is a member, and which do not need to be expressed syntactically.

We may say that the first type of internal arguments represents part of the predicate's syntactic as well as its semantic valency, while the second type only constitutes part of its semantic valency. On the discourse level, the latter may or may not evoke or retrieve a discourse referent. The distinction between the two types of valency may be seen most clearly in the structure of passive and middle verbs, where in the former case, the prepositional agent phrase (...by NP) is most commonly considered to be an optional adjunct syntactically (i.e. it is not part of the verb's syntactic valency), but its referent is nevertheless part of the semantic valency of the predicate at issue. In the case of middle verbs, the agent phrase is (usually) not realized syntactically, though an agent is nonetheless part of these verbs' semantic valency (cf. Mauner et al., 2002).

\section{The semantic and discourse-referential status of implicit arguments}

A further three-way distinction is needed within the category of implicit internal arguments itself, in terms of the semantic and discourse-referential properties and behavior of the zero expression: that is, amongst non-referential (generic or indeterminate), referential-(in)definite (discourse-new) and anaphoric (contextually definite) internal implicit arguments (cf. Fillmore, 1986, Groefsema, 1995, Lambrecht \& Lemoine, to appear 2006, García Velasco \& Portero Muñoz, 2002, Larjavaara, 2000, Berrendonner, 1995, Mejri \& François, to appear 2006, Noailly, 1998a, 1998b and others, for similar but not identical distinctions).

\subsection{Non-referential (generic or indeterminate) implicit arguments}

In the first of these three uses, the non-realized $\mathrm{A}^{2}$ or $\mathrm{A}^{2}$ and $\mathrm{A}^{3} \operatorname{argument}(\mathrm{s})$ of potentially transitive verbs, adjectives etc. may have a non-specific or generic value, in which case the identification of the intended referent is communicatively unimportant, the speaker not having any particular object in mind. This phenomenon is close to an "absolute" use of the predicate concerned, whereby it is virtually equivalent to an intransitive predicate, the focus being placed on the action, process or state evoked via that predicate as applied to the referent of the subject expression ${ }^{4}$. However, the verb in question's semantic valency will not have been affected by this phenomenon, as Noailly (1998a: 377) points out in the case of French. It is only in syntactic terms that we can say that such uses are intransitive. In general, such occurrences do not give rise to a discourse-referent at the level of discourse. What seems to happen here is that the predicate's selection restriction (part of its core sense) is simply transferred to the unrealized non-first argument, so that the latter assumes these very general characteristics ("sawable objects - typically logs" for saw and "trees, shrubs and/or bushes" for prune in (3a), "reading matter" for read and "writing matter" for write in (3c), for example).

Goldberg (2001: 512), like Lehrer (1970), also suggests an analysis in terms of semantic selection restrictions, though in relation to English causative verbs. She contrasts the verbs recycle (where the object of the recycling is specifically 'garbage' of some kind) and break, where, similar to cut or hit, the object broken is only understood as being a rigid,

\footnotetext{
${ }^{4}$ Examples seen so far would be the cognate arguments in (2a) and (2c) in $\$ 2.1$ above. See also Goldberg (2001) for further discussion in relation to English causative verbs.
} 
breakable object. Hence, according to Goldberg, the semantic contribution of the Patient argument is too unpredictable for it to be unrealised syntactically:

(3) a That man always recycles.

b *That man always breaks. (Goldberg's, 2001 examples (22a, b), p. 512)

With regard to (3a) (a constructed example), I can vouch for its possibility of occurrence as an utterance-token, with the following attested example involving four otherwise transitive verbs with unrealized second arguments (here the indeterminate nature of the references in each case is clear):

(3) a' [Notice on individual dustbins on pavements in a street in Canterbury, UK:] "Recycling is so easy when it's collected from your doorstep."

As we will see below, the second argument of recycling (as in Goldberg's example with the predicate in verbal form, in (3a)), is an "inherent" argument, part of the meaning of this predicate only; thus no discourse referent is evoked, and the pronoun it in the second clause of the example has the same, generic, stereotypical referential value as does this inherent argument. Note further here that recycle is an activity predicate aspectually, whereas break is an accomplishment when intransitive, and a causative accomplishment when transitive, in Vendler's (1967) typology of Aktionsart types. These categories will be important in what follows (see this section and section 4 in particular).

The restriction referred to above would explain the impossibility of the realisations in $\left(1 \mathrm{a}^{\prime}-\mathrm{c}^{\prime}\right)$, since none of the verbs see, place or hit places any specific semantic selection restriction on its non-first argument(s) - but see the possible use of hit in the definite past tense with a referential null complement in the attested example $\left(2 \mathrm{c}^{\prime \prime}\right)$. Note also that while the sentences in (2) designate atelic situations (activities - (2a,c) and a property (i.e. a state) (2b)), those in (1) denote telic ones. As we shall be seeing in more detail below, when the host verb is construed atelically, the non-realisation of the relevant non-first argument(s) is generally possible. Examples already seen are those in (2) as well as the occurrence of the normally accomplishment verb kill in $\left(2 \mathrm{c}^{\prime \prime}\right)$, which is converted to an activity predicate via the non-specific predication in which it occurs, as well as via the fact that its second argument is syntactically null. However, with a telic interpretation (as in (1)), non-realisation is in principle only possible in English where the host predicate imposes a specific selection restriction on the relevant internal argument(s).

This non-referential subtype, then, corresponds to Lambrecht \& Lemoine's (to appear, 2006) type Indefinite Null Instantiation. The authors stress that the "unspecified" nature of the reference of the null complement in such cases is not a purely lexical-semantic matter, but is a function of its "pragmatic construal" in discourse. The examples and their analyses below would appear to confirm this view (see in particular the verbs in example (5) below). An example is given by Groefsema (1995, ex. (4a)) in terms of the verb to eat $t^{5}$ :

\footnotetext{
${ }^{5}$ But see $\$ 4.1$ below for an alternative analysis of this example. Groefsema prefixes this example with an asterisk, which I have replaced with the crosshatch (since the example is not ungrammatical qua sentence, but self-contradictory as an utterance).
} 
(4) \#John brought the sandwiches but Ann didn't eat $\boldsymbol{\sigma}$ - she ate the cakes instead.

In (4), the verb eat may be used intransitively, but with an $\mathrm{A}^{2}$ that is subject to a general selection restriction of the type $<$ food $>$. In this use, the second conjunct of (4) would mean that "Ann did not eat any unspecified food" (in other words, she didn't eat anything at all, whence the incoherence of the integration of the content of the last clause of this fragment, which says that she ate some cakes). Thus there is no retrieval of the referent 'the sandwiches which John brought', and hence a restriction to just those foodstuffs. In fact, given the "activity-focus" interpretation of eat here, we may say, as do Koenig \& Mauner (2000), that no real internal argument at all is involved here, the verb eat having its "absolute" sense as a property-attributing predicate. Koenig \& Mauner (2000) would call the non-referring internal argument of eat in (4) an "a-definite". An "a-definite" is an implicit argument which does not evoke a discourse referent, since it is neither definite, nor indefinite, but partakes of both values simultaneously; all that such implicit arguments do is satisfy the argument position of the predicate which they "fill". Van Valin \& LaPolla (1997: 123) call such arguments "inherent arguments", a notion which they define as follows: “... an argument which expresses an intrinsic facet of the meaning of the verb and does not refer specifically to any participants in the event denoted by the verb; it serves to characterise the nature of the action rather than to refer to any of the participants."

An attested example is the following advertisement in The Sunday Times for a motor show, involving four otherwise transitive verbs with unrealised second arguments (here the indeterminate nature of the references in each case is clear):

(5) “See, try, admire or buy at London's Motor Show." (Advertisement, The Sunday Times, 9.10.83, p. 9)

The types of things which the reader of the advertisement in (5) is enjoined to "see, try, admire or buy" (note the imperative mood of these predications, which favours non-realisation) are clearly new models of motor vehicles and their accessories, exhibited in the Motor Show to which the utterance is referring. We thus have a set of - fairly general, in all these instances selection restrictions transferred by the senses of each of the predicates involved to their noninstantiated $\mathrm{A}^{2} \mathrm{~s}$, senses which are delimited to a denotation type via the context in which the text occurs - an advertisement for a Motor Show. Such arguments would not receive a macrorole in Van Valin \& LaPolla's (1997) Role and Reference Grammar model, no discourse referent being introduced in order to be the object of subsequent predications.

As Mejri \& François (to appear, 2006) point out, it is necessary to distinguish between indeterminate (as I shall call this sub-type) and generic values of null complements. The type in (4a') ("Recycling is so easy when it's collected from your doorstep.") could be argued to be generic, since the (initial) clause as a whole is generic: the tense is the (gnomic) present, and the predication attributes a property to an event type as opposed to token. Whereas in (5), the four predications are eventive, the conjuncts each being in the imperative mood, and the actions enjoined being located within a specific commercial event. The null complements thus all have an indeterminate, rather than generic value here. In both cases, it is the event (token

\footnotetext{
${ }^{6}$ The authors' key example is the short passive, where the implicit internal argument is interpreted as the unspecified agent of the result of the action denoted: (1a) A ship was sunk.
} 
or type) denoted by the verbal predicate which is highlighted by the null complement realisation, its participants being backgrounded thereby. See also the use of kill in (2c'") ("...it would have been moving fast enough to kill on the spot..."), whose null complement would appear to have an indeterminate (human-denoting) value here ("people, whoever they might be").

One possible test of whether a zero expression as null complement of a given predicate is interpreted as generic/indeterminate ("indefinite", in Fillmore's terminology) or referential (anaphoric, in this case: "definite" for Fillmore) is proposed by Fillmore (1986: 97):

(6) a He was eating ; I wonder what he was eating.

b They found out ; \# I wonder what they found out.

That there is an internal argument here is indicated by the fact that it makes sense to ask a question in instances such as (6a): after all, with purely intransitive verbs (both syntactically and semantically), such as die, a question of this sort would be absurd (John died - *What did John die?). The indirect question in the second clause of (6a) is semantically appropriate, however, since the nature of the food being eaten, as evoked via the first clause, is unspecified and communicatively unimportant: the argument is only "inherent", in Van Valin \& LaPolla's (1997) terms, or "a-definite", in those of Koenig \& Mauner (2000). In the case of the predicate find out in (6b), on the other hand, the zero complement does have a contextually-identifiable (and thus 'discourse-') referent, which is presupposed to be known and highly accessible to the addressee at the point of occurrence. Another reflex of the distinction lies in the fact that intransitive eat in (6a) is an activity predicate which does not require any particular context for its occurrence; while find out in (6b) is an achievement predicate in terms of Aktionsart, which clearly does require a particular context for its occurrence to be felicitous (one in which the intended referent of the null complement is made salient in some way). But the test illustrated in (6) does not enable us to distinguish between generic/indeterminate and discourse-new implicit arguments, as illustrated below in (7) and (8).

\subsection{Discourse-new referential implicit arguments}

Another value assumable by implicit internal arguments is that of evoking a discourse referent which may later be retrieved, under certain conditions, via an anaphor. This value is termed a "latent object" (objet latent) by Larjavaara (2000) (Larjavaara 2000:51 conflates under this term the discourse-new and the anaphoric use of such zero arguments; what is crucial here is that the zero form's intended referent be identifiable ${ }^{7}$ by the addressee, or at least that it be treated as such by the speaker. Whether or not it is salient at the point of occurrence in the cotext is immaterial). This corresponds to both of Mejri \& François' (to appear, 2006) subtypes "latent-identifiable" and "latent-identifiable and salient". It corresponds in part to Lambrecht \& Lemoine's (to appear, 2006) type Free Null Instantiation, where "the referent can be either

\footnotetext{
7 "Identifiable" only after the clause has been processed, however, since this occurrence would be substitutable in context by an indefinite, but not a definite, NP (I am indebted to Nancy Hedberg for pointing this out). As such, this occurrence would correspond to the cognitive status "referential" in the Gundel, Hedberg \& Zacharski (1993: 276) "Givenness Hierarchy" (see $\S 5.2$ for further discussion), defined as follows: "the addressee must either retrieve an existing representation of the speaker's intended referent or construct a new representation by the time the sentence has been processed."
} 
specific or non-specific, the choice of interpretation being left up to the hearer" (MS. p. 5). The first conjunct of (7) below provides an initial example:

\section{(7) I wrote o to you a week ago, you know, but you never answered $\boldsymbol{\text { ! }}$}

In (7), the context indicates that the verb write is being used in its "correspond" sense; the predicate at issue therefore has three arguments, the second of which is unrealized syntactically. This non-instantiated $\mathrm{A}^{2}$ argument ('a letter sent by the speaker to his/her interlocutor a week before the time of utterance') is clearly referential, owing to the definite past tense chosen here, and the reference to a specific event which occurred prior to the utterance of (7). It is equally clearly discourse-new, being an introductory reference (even though the intended addressee may already be aware of the existence of such a letter), the referent constituting discourse-new information in context. Unlike the "generic/indeterminate" values of null complements seen in $\S 3.1$, the "referential- (in)definite" use does introduce a discourse referent (and would clearly warrant the assignment of a "macro-role" in terms of RRG). See also the example given in (13a) in sub-section 4.1 below, where the zero complement would correspond to a definite, but not indefinite, NP.

Other examples of discourse-new null complements can be found in deictic occurrences, where the referent is potentially available to the addressee from within the utterance context, but not yet salient (i.e. topic-worthy). Typically, such instances occur in imperative contexts, within a non-specific context), where the interlocutive relationship is highly constrained:

\section{(8) Eat ø!/Watch ø!/Mind ø!/Smell ø!/Taste ø!}

In each such case, the interlocutor's attention is being specifically drawn to the thing or event involved, which is available within the situational context. As such, it is thereby made salient for both participants.

\subsection{Anaphoric (contextually-definite) implicit internal arguments}

A third possibility is where the implicit $\mathrm{A}^{2}$ argument is not only referential and identifiable, as in the case of the null $\mathrm{A}^{2}$ complement of wrote in (7) above, but anaphoric. The second noninstantiated $\mathrm{A}^{2}$ argument in (7), the referent of the null complement of answered in the second conjunct, is contextually definite, in contrast, as it is construed as referring back anaphorically to the letter introduced by the null complement in the initial conjunct. Fillmore's (1986) test for "indefinite" (non-referential, of the type seen in $\$ 3.1$ above) null complements would be clearly negative here: ...\#I wonder what you never answered (see also examples (2)a" ${ }^{\prime \prime} \mathrm{B}$ ) and $\left(2 c^{\prime \prime}\right)$ ). This subtype corresponds in part ${ }^{8}$ to Lambrecht \& Lemoine's (to appear, 2006) type Definite Null Instantiation.

Given that I include under the heading "anaphora" exophoric uses of potentially anaphoric expressions ${ }^{9}$, I would subsume under this value such uses of zero complements - as in the case of labels on bottles of pharmaceutical products, instructions for use etc. of the type:

\footnotetext{
${ }^{8}$ I say "in part", since Lambrecht \& Lemoine make clear that their category "Definite Null Instantiation" covers not only anaphoric, but also discourse-new, identifiable referents of the zero complement. Thus, such zero complements would not be substitutable by an unaccented pronoun, but rather by a relevant definite full NP.

${ }^{9}$ See Cornish (1999: ch. 4) for arguments in favour of this move.
} 
Take $\boldsymbol{o}$ with precaution (label on bottle of medicinal pills); Break $\boldsymbol{o}$ in an emergency (instruction displayed on a glass panel behind which is placed an alarm). The host verbs in such examples are in the imperative mood, like the deictic examples in (8). However, it is clear that the intended referent of the zeros in such 'label' cases is not only identifiable, but salient and (potentially) topical: the addressee's attention is assumed, in such "caption-like" instances, to be already centred on the object on or under which the notice is placed. Thus the implicit argument is contextually-definite, and the reference is anaphoric (cf. the infelicitous queries: \#...I wonder what should be taken with precaution/\#...I wonder what should be broken in an emergency, respectively).

As a further example, let us give the second member of the minimal pair of examples presented by Groefsema (1995) (her (4b)):

(9) The guide left but the tourists didn't follow - they followed the courier instead.

In (9), unlike the use of eat illustrated in (4), the zero form with which the verb follow is constructed in the second conjunct may well retrieve the contextually definite referent 'the guide who left', since, according to Groefsema (1995), in the lexical-semantic structure of this verb there is a selection restriction which requires a particular occurrence of a thing (here it is an event) corresponding to a given type. Follow would thus be a verb allowing a definite (and not indefinite) null complement, in Fillmore's terms. Fillmore's (1986) test given under (6) is again negative here, as with his example verb find out: The guide left but the tourists didn't follow ; \# I wonder who they didn't follow.

\section{The anaphoric potential of null complements, event structure and predication}

\subsection{Interpretative values of complement zeros vs. overt object pronouns}

Concentrating from now on essentially upon the contextually-definite, anaphoric function of null complements, we can say, first of all, on the basis of the discussion in sections 2 and 3 , that this is possible in English under two main conditions: first, there must exist a specific selection restriction upon the non-first argument(s) subject to non realization in terms of syntax. The second condition is evidently that the null complement's referent be contextually salient and topical, a condition generally holding on the existence of anaphora; however, in the case of English, this condition is only a necessary, and not a sufficient one, as example (10) clearly indicates.

(10) Martin liked the look of the pair of walking shoes displayed in the store window: he went and bought *o/them without trying *o/them on.

Here, the verb buy is used in the definite past tense, and the reference is clearly to a specific occasion of buying something - a pair of walking shoes - and of not trying that something on. But even though this referent is contextually salient as well as topical, this is not sufficient to permit the non-instantiation of the internal argument of the two verbs concerned under an anaphoric (coreferential) reading ${ }^{10}$. It would seem to be the non-specific nature of the

\footnotetext{
${ }^{10}$ See also the ill-formed examples of 2- or 3-place achievement or accomplishment verbs with null complements in (1) above - where the tense is also the definite past, and the intended referent of the null complement may also be contextually salient.
} 
selection restriction associated with the lexical-semantic structure of these verbs which prevents this type of functioning. The verbs buy and try on seem to have only very general selection restrictions (respectively, <commodity $>$ and $<$ clothing $>$ ). In spontaneous spoken French, however, the equivalent verbs may well occur with a null complement, under an anaphoric interpretation: see the French equivalent of the final clause in (10): ...Il est allé $\boldsymbol{o} /$ les acheter sans $\boldsymbol{o} /$ les essayer. In English, only an overt pronoun may occur as complement of the verbs in such a context.

What now of the difference in behaviour of null complements and unaccented overt pronouns? In this respect, Groefsema (1995: 156) gives a telling minimal pair, but which she does not further analyse. Here the null complement in (11a) is "indefinite" (though still anaphoric) and not contextually definite:

(11) a John picked up the glass of beer and drank .
b John picked up the glass of beer and drank it.

In (11a), what John is said to have drunk is some, not necessarily all, of the beer in the glass evoked via the initial conjunct (i.e. the null complement entails a partitive reading here). The zero is anaphoric, but the null instantation of this predicate's $\mathrm{A}^{2}$ has had the effect of changing the accomplishment Aktionsart evident in (11b) with the pronoun into an activity predication. In (11b), by contrast, John is stated as having drunk all of the beer in the glass (the overt pronoun enabling the accomplishment event structure to be specified, and inducing a holistic interpretation). The anaphoric, and not "indeterminate", non-referential value of the zero in (11a) is determined by the fact that the two conjuncts of this example designate a sequence of two specific events (note the definite past tense borne by the verbs in each conjunct) which each form an integral part of a more global event.

Groefsema's analysis of the null complement evident in (11a) highlights the fact that the verb drink does not (in the absence of a syntactically-realized direct object) place any specific selection restriction upon its internal argument (technically, in terms of Jackendoff's, 1990 Lexical-Conceptual model), other than that it be a THING (type of entity) of the type "liquid" - but certainly not an "instance" of a THING (i.e. token or occurrence of a THING). However, the reader of (11a) will certainly understand the null complement of drank as referring to (a quantity of) the beer evoked in the initial conjunct, and not of any unspecified type of beverage.

Lehrer (1970: 245) gives a similar minimal pair involving the verb drink, but the interpretation possibilities associated with the use of the null complement versus the pronoun are rather different:

(12) a John drinks only gin, but I won't drink ${ }^{11}$.

b John drinks only gin, but I won't drink it. (Lehrer, 1970: examples (67) and (68), p. 245)

For Lehrer (1970: 245), the interpretation of the null complement in (12a) is the generic one 'alcoholic beverage', and not 'gin' as such. This is the default interpretation associated with

\footnotetext{
${ }^{11}$ Note that this utterance is not fully acceptable as it stands. A more natural rendering of the second conjunct would involve replacing the negative modal auxiliary won't by the neutral don't, expressing a more objective property of the subject referent, and adding the negative emphatic particle at all: ...but I don't drink at all.
} 
the 'absolute' use of intransitive drink (the domain of 'alcoholic drinks' is set by the reference to "gin" in the initial conjunct). In (12a), unlike (11a), there is no (partitive) anaphoric interpretation available for the zero complement of drink, since each predication denotes an atemporal property (via the simple present tense in each conjunct and the lack of an article in the NP gin), the second property holding independently of the first. Thus the predication in the second conjunct of (12a) does not continue the situation established in the first, and so the null complement is not anaphoric in value (see Kleiber, 1994: ch. 3). We thus have the generic value, delimited via the reference to 'gin' in the initial conjunct to 'alcoholic beverages', which we saw in $\S 3.1$ (see also example (3a') above). In contrast, in (12b) the definite pronoun is anaphoric, and refers to the type of alcoholic beverage mentioned in the initial conjunct, namely 'gin'.

The situation represented by (11) seems somewhat different, then, from the ostensibly identical example (4) involving the verb eat (also one of Groefsema's examples), where it was claimed that the zero complement of the latter verb is purely non-referential in value (as in Lehrer's example (12a) above), and could not retrieve the referent 'the sandwiches' evoked in the initial conjunct of (4). Fillmore's (1986) test of non-specificity would be negative in the case of (11a) (\#...but I wonder what he drank). It would seem, from examination of just these two transitive/intransitive verbs, that Lambrecht \& Lemoine's (to appear, 2006) intermediate category "Free Null Instantiation" would be relevant as a characterization of their potential uses - either a specific, anaphoric, or a non-specific, quasi-generic interpretation being possible for the complements of such verbs.

I would argue that this systematic difference in interpretation arises because of the fact that overt pronouns are nominals which, because of their inherent definiteness and (potential, at least) referentiality, change the Aktionsart of the verb whose second argument they instantiate, from an atelic activity into a telic accomplishment. Thus with definite complement pronouns, the emphasis is no longer on the activity of drinking (or eating), but on the nature of the thing drunk (or eaten). But this may also be the case even with "incremental-object" verbs like eat and drink, whose Patient argument is understood to be progressively affected by the process involved, even when their second argument is unexpressed syntactically. Compare (13a) and (13b) in this respect ${ }^{12}$ :

(13) a Mary ate ø at noon.

b The waiter served the main course. Mary ate ø hungrily.

In both (13a) and (13b), the tense is the definite past, and the reference is to a specific event which occurred prior to the act of utterance. The null instantiation of the $A^{2}$ in (13a) induces the basic, characteristic activity interpretation of the $\operatorname{verb}^{13}$, but the presence of the contextualising PP at noon overlays this reading with the culture-specific stereotype 'midday meal' as the frame in which the event denoted is to be set, so that the predication as a whole is telic, and not atelic via non-instantiation of the $\mathrm{A}^{2}$. This is clearly a referential instance, but a "discourse-new" one rather than an anaphoric, context-bound instance. It is a frame-based

\footnotetext{
${ }^{12}$ I am indebted to the anonymous external reviewer for example (13a) and its relevance to the point at issue here.

13 See Van Valin \& LaPolla (1997: 112) for arguments that verbs of consumption such as eat and drink are basically activity verbs in terms of Aktionsart, which may be used transitively as accomplishment predicates. See also Mittwoch (1982) on the difference in Aktionsart between eat and eat something.
} 
occurrence, trading on the cultural knowledge that meals (in most Western societies) normally take place at or around noon every day.

But in (13b), the presence of the manner adverb hungrily highlights the basic activity sense corresponding to the predicate's inherent value (since it directly modifies the activity subeventual structure underlying this predicate lexical-semantically). There is no implicature available such that Mary actually finished eating the main course which she has been served. Thus the zero has the indeterminate, non-referential value which we saw in the case of the verbs in (3) and (5). If we apply Fillmore's "I wonder what $X V$-ed" test, it is positive in (13b) ("I wonder what Mary ate"), but negative in (13a) (with the predicted response "\#She ate a midday meal"; however, with the type of response expected and normal for the same query on (13b) - e.g. "....chicken and noodles" -, it is positive). The bounded/non-bounded adverbial tests also discriminate the two occurrences: for (13a) Mary ate ø at noon ?\#for ages/in an hour; and for (13b) Mary ate ø hungrily for ages/\#in an hour .

With hindsight, it appears that what prevented the null complement of eat in (4) from functioning anaphorically was the fact that it occurred in the scope of the negation, preceded by the expectation-denying conjunction but. If we remove these two elements, the anaphoric interpretation is not only possible, but highly expected:

\section{(4') John brought the sandwiches, and Ann ate hungrily.}

Here, the same "partitive" interpretation seems to come to the fore as in the case of the null complement of drank in (11a): that is, we understand in (4') that WHAT Ann ate were the sandwiches which John brought, but that she didn't necessarily eat all of the sandwiches that he brought - only some of them. This seems to contradict Groefsema's (1995) prediction here, as well as an identical one made for this verb by Van Valin \& LaPolla (1997: 122) using a very similar example.

However, as in the case of the use of the overt pronoun it in (11b), if we replace the zero complement in $\left(4^{\prime}\right)$ by the overt pronoun them, then the same holistic interpretation as in (11b) naturally presents itself. The situation is thus somewhat more subtle than Groefsema (1995) implies, since it clearly involves a complex interaction between lexical-semantics, syntactic realization (or non-realization, as the case may be) and discourse function ${ }^{14}$.

\subsection{The roles of Aktionsart and event structure: "content" vs. "(event-) structural" arguments}

Rappaport Hovav \& Levin (1998: 104ff.) and Brisson (1994) also claim that it is the aspectual structure of the verbal predicates concerned which determines whether or not their $\mathrm{A}^{2}$ argument may be left unrealized: however, it is not the static, inherent lexical-semantics of each individual verb which is relevant here, but the compositional semantics of the predicative unit as a whole (verb + possible extra adverbial element) - see also Ritter \& Thomas Rosen (1998) and Van Hout (1999), as well as the contrast between (13a) and (13b) above.

Both Brisson and Rappaport Hovav \& Levin claim that the non-realization of internal arguments is only possible when the argument at issue is a "content", and not a "structural" one. The distinction involves that between the aspectual or "event structure" of the sentence as a whole, where the participants involved are "structural participants", and the lexically-

\footnotetext{
${ }^{14}$ Cf. also Goldberg (2001).
} 
specific content of the predicate which "heads" that structure. This predicate brings with it a certain array of arguments in terms of its meaning: these are the "content" arguments. Thus there may be a discrepancy between the two types of structure. Brisson argues that ("activity") verbs of the type illustrated by sweep (plough, pack, dust, vacuum, clean, mow, rake...) may occur with either a durative or a bounded time adverbial ${ }^{15}$, whether with or without a syntactically-realized object NP, and whether this NP is definite or indefinite. This would give the predicate 'sweep' (as well as the others in its class) the "content" structure sweep (x,y) but the event structure 'activity (x)'. From Brisson's account, one can infer that the ' $y$ ' argument in the content structure is more or less totally determined by the meaning of this predicate (stereotypically, a 'floor' of some kind) - an "inherent" or "a-definite" argument, then; whereas, given that this verb is basically an activity predicate (as indicated by the various tests applied to it), there would be no second, $\mathrm{A}^{2}$ argument at this event-structural level at all (in Van Valin \& LaPolla's 1997 terminology, the predicate's content $\mathrm{A}^{2}$ argument would not correspond to a "macro-role"; the verb in question would thus be "M-intransitive", bearing only one macro-role argument).

Now, given that this is the case, the sole $\mathrm{A}^{2}$ "content" argument, not being a "structural" one, need not be realized syntactically - so long as its essential content is contextually recoverable. This is the case with verbs of the type represented by sweep, where general knowledge tells us that it is typically 'floors' that are swept (see also plough $\rightarrow$ 'fields', pack $\rightarrow$ 'suitcases', dust $\rightarrow$ 'furniture', vacuum $\rightarrow$ 'carpets', clean $\rightarrow$ 'artefacts', mow $\rightarrow$ 'lawns', rake $\rightarrow$ 'leaves', etc.). This general class of predicates is characterized by Rappaport Hovav \& Levin (1998: 99) as "verbs of surface contact through motion". The situation described here would seem to characterize the first type of non-realization of nonfirst arguments seen above in $\S 3.1$ (the non-referential generic/indeterminate argument type).

On the other hand, where a given predicate has a causative accomplishment or achievement interpretation, there is necessarily a binary event structure involved, consisting of a causing event (an activity) and a resulting state. Thus there are inevitably two structural arguments, both of which must be realized syntactically, according to these authors. This would explain then why such predicates (for example, English break, as we have seen) cannot leave their $\mathrm{A}^{2}$ argument unrealized. Break is an "externally-caused change of state verb", according to Rappaport Hovav \& Levin (1998: 99). The content structure of break would then be break (x,y), and its event structure 'activity (x) CAUSE [BECOME broken y]', where broken represents both the essential content of the predicate 'break' and its status as 'resulting state' of the macro-event involved here ${ }^{16}$. See Van Valin \& LaPolla's (1997: 107) representation of the Aktionsart structure of causative break in their example (3.24). It can be argued that the intransitive, inchoative use of break (as in The vase broke) is more basic, and that the transitive-causative use is derived from it by rule. I have attempted to formalize these two types of structure under (14a and b) below, drawing inspiration from the notation system used in Van Valin \& LaPolla (1997) ${ }^{17}$.

\footnotetext{
${ }^{15}$ However, my feeling is that examples like Brisson's (unstarred) (9b) (p. 91) Jack swept in an hour are not fully acceptable. One of the editors of this volume, Nancy Hedberg (p.c.), indicated agreement with this judgement.

${ }^{16}$ I have inserted the abstract operators CAUSE and BECOME here, as well as the square brackets, which Brisson does not do; indeed, she does not represent the structure of break in her article.

17 The segment in parenthesis following ' $\neg$ intact' (y)' is intended to capture the selection restriction imposed on its single argument by the meaning of this predicate. For the inchoative 'activity' or 'process' value, the segment preceding the operator BECOME in (19b) would not be instantiated.
} 
(14) a "Content structure" of core sense of break, after Brisson (1994) and Rappaport Hovav \& Levin (1998):

BECOME $\neg$ intact' (y) ((partially_)rigid_object, y)

b "Event structure" of break, after Brisson (1994) and Rappaport Hovav \& Levin (1998):

[[activity (x)] CAUSE [BECOME $\neg$ intact' (y) ((partially_)rigid_object, y)]]

Brisson's (1994: 97) two licensing conditions on the possibility of unexpressed objects are given below:

(15) a Grammatical licensing condition: structure arguments must be expressed. (Brisson, 1994: (24))

b Contextual licensing condition: the unexpressed object must be understood. (Brisson, 1994: (25))

Rappaport Hovav \& Levin (1998) formalise and further develop Brisson's essential insights. They propose two well-formedness conditions on the syntactic realization of event structures, as follows:

(16) Subevent Identification Condition

Each subevent in the event structure must be identified by a lexical head (e.g. a V, A or P) in the syntax. (Rappaport Hovav \& Levin, 1998: 112)

(17) Argument Realization Condition

a. There must be an argument XP in the syntax for each structure participant in the event structure.

b. Each argument XP in the syntax must be associated with an identified subevent in the event structure. (Rappaport Hovav \& Levin, 1998: 113)

Condition (17a) makes more precise Brisson's (1994) "Grammatical licensing condition" given under (15a) above; while Condition (17b) ensures that all argument expressions in the syntactic realization be relatable to a predicate corresponding to an identifiable subevent in the event structure associated with the sentence. Condition (16) completes the picture, in that it ensures that each predicate marking a subevent in the event structure be relatable to a relevant lexical head.

However, it would seem that these conditions are much too rigid and absolute: they do not take enough account of the surrounding co-text or context of occurrence of the verbal predicates at issue here - i.e. of the way in which these predicates are actually used. If we take the (causative accomplishment) verbal predicate break as a typical verb having a binary event structure, with two content and two structural arguments, the prediction is that non-realization of the $\mathrm{A}^{2}$ argument is excluded - as we have seen. In the case of the non-referential generic or indeterminate use of the verb, of course, the authors could claim that what we have is an activity, such that there is no longer a second structural argument since the binary event 
structure is no longer available. This could occur in the following kind of situation: imagine a warehouse full of trestle tables on which are piled substandard mass-produced cups, plates and saucers etc., all containing imperfections of one kind or another. Members of the public are invited to break these items into pieces, so that they can more easily be recycled. On the entrance to the warehouse is pinned a large notice, with the words:

\section{(18) Break ø to your heart's content!}

Clearly, this would correspond to the indeterminate, "absolute" use of transitive verbs with unrealized complements that we saw in $\S 3.1$, with the context-of-utterance delimiting the type of things to be broken as items of reject crockery on the tables in the warehouse. As already noted, this use would not constitute a counter-example to Brisson's and Rappaport Hovav \& Levin's constraints (since in this usage, break and similar verbs would be activity and no longer achievement or accomplishment predicates; as such, they would be only unary event (i.e. activity) predicates). But there are two other possibilities with break. The first is the possible deictic use which we briefly saw in $\$ 3.2$, where the null complement of break has a referent available via the utterance situation. As an example, consider again the "reject" crockery situation evoked a moment ago. Imagine a situation where a member of the public has entered the warehouse and has been merrily smashing plates, cups and saucers for the last 20 minutes. Suddenly, he comes upon a large bowl with an attractive design, which doesn't seem to him to be in too poor a condition. As he holds it up to examine it, the attendant walks towards him and says:

\section{(19) Come on now, break ø! They've all got to go, you know!}

Here, the referent is clearly present, both at the semantic and the discourse-representational levels - and yet the second "structural" argument is syntactically null, contrary to conditions (15a) and (17a). I believe (19) corresponds to a deictic and not purely anaphoric use of the null complement, since the addressee is tacitly querying the status of the intended referent (thus it consists in introducing the referent qua "non-breakworthy" item of crockery in this context). If an overt pronoun were to be used in place of the zero complement here, I believe it would be the demonstrative pronoun that rather than the (purely anaphoric) $3^{\text {rd }}$ person pronoun it (thus it consists in introducing the referent qua "non-breakworthy" item of crockery in this context). This is the essential function of deixis, under my conception (see Cornish, 1999: §2.3 and Ch. 4). Granted, there are "extenuating" circumstances here, independently motivating the null complement of break, since this type of occurrence is restricted to the type of highly modalized context represented by the imperative mood in (19).

But there is a second type of counterexample to these stipulations, falling within the third of the three cases outlined in section $3(\S 3.3)$. This is the "exophoric" use of predicates like break, which I claimed come under the anaphoric, context-bound use (as in the notice Break $\varnothing$ in an emergency displayed above a glass panel covering an alarm handle). Here too there is an argument at the lexical-semantic level as well as a discourse-referent at the level of discourse. Again, the possibility of such occurrences is a counterexample to stipulations (15a) and (17a).

In all three types of example involving break with a null complement, the clause is in the imperative mood. This is no accident, in fact. What this mood induces (contrary to the 
declarative mood, in particular) is a focussing of attention on the object of the command - the speech-act type typically correlating with the imperative form. This serves, then, to enhance psychologically, i.e. to 'profile', the entity at issue, and thus to allow it to be unrealized syntactically. Though the mood is not imperative in examples like (20) below (suggested to me by one of the editors of this volume, Nancy Hedberg), (causative) accomplishment verbs like cut would nevertheless appear to allow their $\mathrm{A}^{2}$ to be unrealized syntactically, here with a context-bound, partitive anaphoric interpretation.

Mary helped me make paper dolls. She colored and I cut.

As Nancy Hedberg (p.c.) points out, the second sentence here clearly denotes a (complex) activity - but as such, of course, it would not be a counterexample to Brisson's and Rappaport Hovav \& Levin's conditions on syntactic non-realization: the referent of the null complements of the two verbs is contextually recoverable ('(parts of) the paper out of which Mary and the speaker are making paper dolls') - see Brisson's (1994) second condition (15b) above. The example would appear to be parallel to (11a), since the event structure is an activity one, and the event denoted in the second clause continues (or is an exemplification of) that evoked by the first; the zero complements involved are thus identity-of-sense anaphors, retrieving parts of the paper used to make the paper dolls. So although the verb's two content arguments are present, in terms of the event structure of the clause as a whole the predicates at issue are unary ("M-intransitive", in Van Valin \& LaPolla's 1997 terms, the second argument not corresponding to a "macro-role"), and conditions (15a) and (17a) are satisfied.

\section{Taking stock: the role of the host predication in the licensing of null complements}

Let us try now to assess the situation, and arrive at a set of principles enabling us to predict both whether a transitive predicate's second or second and third argument(s) may be unrealized syntactically, and if so what will be their type of interpretation. Clearly, the occurrence of null complements in English needs to be licensed (we have already seen that the principles lying behind this licensing in the case of English are stricter than in that of spontaneous spoken French): for it is clearly not just any transitive verb, in any type of context, which may leave its $\mathrm{A}^{2}$, or $\mathrm{A}^{2}$ and $\mathrm{A}^{3}$, unrealized syntactically. More precisely, there are two main questions to be addressed here:

1) Under what circumstances may a predicate's $\mathrm{A}^{2}$, or $\mathrm{A}^{2}$ and $\mathrm{A}^{3}$, be unrealized syntactically?

2) What determines whether these unrealized arguments will receive a non-referential (generic or indeterminate) interpretation, or a referential discourse-new reading, or an anaphoric one?

Clearly, these questions are linked. Thus, an answer to question 2 will enable us to provide an answer to question 1. Let's take question 1 first, but taking into account considerations relating to question 2 .

\subsection{Aktionsart, event structure and selection restrictions}

First of all, it is clear that it is easier for a null complement to occur with an otherwise syntactically-transitive predicate in English when it can be interpreted non-referentially "generically" or "indeterminately" (the so-called "absolute" use of transitive predicates) - than 
when it is to be understood referentially (in either the discourse-new or anaphoric use). This is evident from a comparison between (5) and (10), reproduced below for convenience.

(5) "See, try, admire or buy at London's Motor Show."

(10) Martin liked the look of the pair of walking shoes displayed in the store window: he went and bought *o/them without trying *o/them on.

In (5), the transitive verbs used "absolutely" occur within an atelic utterance, where the verbs are in the (imperfective) present tense. The predications are thus all atelic, and the implicit arguments are understood in terms of the selection restrictions of the predicates at issue, a denotation which as we have seen is delimited by the context of utterance of the clause concerned. No discourse referent is evoked. We may say then that, in principle, any syntactically transitive verb, when occurring in a non-perfective tense-aspect within an atelic or generic clause (or one which in context can be interpreted as atelic or generic), may allow its non-first argument(s) to be unrealized syntactically - but only insofar as there exists a socio-cultural stereotype which can license such a conceptual category. One test of the existence of such an argument type is the naturalness of an indirect question posed regarding the nature of this argument (cf. ...I wonder what $X \mathrm{~V}$-ed/-s). If in the context of the utterance containing the null complement it is natural to pose such a question, then first, there must be an argument of some kind; and second, the argument in question is either generic (nonspecific) or indeterminate in reference. In both such cases, it makes sense to query this entity, precisely because it is indeterminate, or non-specific. In neither of the other two types of value is it natural to question the implicit argument.

In example (10), by contrast, the verb buy appears in the simple past tense in a predication which designates a specific occurrence of an action. As we have seen, even though the intended referent is contextually identifiable and salient and topical at the point of occurrence, the complement of buy cannot be null under this construal. We have ascribed this impossibility to the lack of a specific selection restriction imposed on this argument position by the lexical-semantics of this predicate (one can "buy" all sorts of physical objects, conceived as "commodities" of one kind or another).

On the other hand, where a transitive predicate's "internal" selection restrictions are specific, this, in conjunction with the context-boundness (and saliency, when an anaphoric occurrence is at issue) of the intended referent, may be sufficient for the null complement to occur. This is illustrated in example (7) (I wrote to you a week ago, you know...) where the predicate write (an accomplishment predicate) in the context of an exchange of correspondence between speaker and addressee, imposes a sufficiently specific selection restriction upon the $\mathrm{A}^{2}$ argument for the referent to be identifiable in context (in the sense specified in note 7). Write, like drink, is an 'incremental-object' verb (cf. van Hout, 1999), whereby the existence of the thing(s) written (or drunk) increases in proportion to the time over which these predicates obtain.

The interaction between the intrinsic aspectual properties of host predicates, on the one hand, and the event-structure of the containing clause as a whole (together with aspects of the context of utterance, including the availability of culturally-specific stereotypes) would seem to operate as follows. Aspectually, activity verbs (including incremental-object predicates) may occur with a null complement bearing a referential value when the co(n)text is such as to induce a specific, time-bound event. This is the case in (13a), where the temporal-locative 
adverb at noon, coupled with the choice of the definite past tense, induces a referential construal of the null complement of ate, thereby introducing the discourse-new referent 'Mary's midday meal' into the discourse. Ate is still an activity predicate, but the predication as a whole takes on an accomplishment aspectual value, as when this verb's second argument is lexically instantiated via a definite referential NP.

Conversely, state, accomplishment and achievement verbs involving direct contact (physical, communicational, visual or mental) entail the immediate presence of the entity involved as a whole. Where the verb at issue is not one of consumption or durative creation, there is no gradual, progressive application of the predicate to the entity, or resulting in the appearance or disappearance of the entity. Thus in the absence of relevant context, there is no "activity" induced via the non-realization of these predicates' $A^{2}$. Hence, the expected value of the null complement in these cases is in terms of one of the two referential (discourse-new or anaphoric) interpretations. Yet, as with activity predicates, the co(n)text may induce an opposite aspectual value (here, an activity reading), and thus assign the null complement the indeterminate, non-referential value (see examples (5), (18) and (20)). Given contexts may well sanction occurrences of such predicates where their unexpressed complement has a referential value, in situations where they have two event-structure arguments (see the occurrence of hit in (2c' ) and of break in (19)).

This is a clear violation of constraints of the type in (15a) and (17a) - but the works in which these constraints were formulated were based exclusively on invented, context-free examples, and did not take account of actual, attested data. In the case of incremental-object and activity verbs, there is a preference in terms of aspectual predicate type for either of the two non-referential (generic or indeterminate) values of the null complement; and in that of state, accomplishment and achievement verbs, there is a preference in terms of one of the two referential values for these complements - though in English, there must be a selectionally- or contextually-induced denotation type made available for this to be possible (cf. hit as used in $\left(2 \mathrm{c}^{\prime \prime}\right)$ in contrast to buy in (10)). But the opposite values may be induced via contextual triggers - features of the co-text or the context (or both), as well as the accessibility of given cultural stereotypes.

\subsection{Referential pragmatics: cognitive status, the Givenness Hierarchy, and one neo-Gricean account of anaphoric complement zeros vs. overt object pronouns}

As far as the pragmatics of zero forms is concerned, these are said by linguists such as Givón and Ariel to be extremely high accessibility markers. Indeed, they figure at the extreme "High Accessibility" pole of Ariel's (2001: 31, item (2)) Accessibility Marking Scale, where each referential expression-type is assigned a degree of accessibility relative to the status of its intended referent in the addressee's memory, as assumed by the speaker at any given point in a discourse. Zero forms do not figure at all in Gundel, Hedberg \& Zacharski's (1993; 2000) "Givenness Hierarchy", though as Nancy Hedberg (p.c.) points out, in their (1993) article, these authors did include zero NPs on the Givenness Hierarchies which they postulated for Spanish, Chinese, Japanese and Russian, claiming that their referents are of necessity in focus.

This is no doubt the case with the null complements in English and French which have the third of the three values isolated in this chapter (i.e. the context-bound, anaphoric function), and this was no doubt also what Ariel had in mind in placing zero forms on her Accessibility Marking Scale (however, Ariel predominantly illustrates and discusses subject 
zero forms, to the exclusion of complement ones). The first type isolated above (the nonreferential "inherent argument" type, in Van Valin \& LaPolla's, 1997 terms - see sub-section 3.1 above) would of course not be relevant here, since it is bound up with the predicating ability of the verb in question, and has no referential force.

However, the second type, depending on whether it is construed as hearer-new or hearer-old (a frame-based value), would not necessarily encode high accessibility: for the "hearer-new" variant, the intended referent is relatively inaccessible, since it is being introduced brand-new into the discourse; and for the "hearer-old" variant, the referent is midway accessible, being "expected" in terms of the knowledge frame currently being evoked, but nevertheless new in terms of the current discourse (i.e. its discourse-pragmatic value would be "hearer-old" (in terms of "inferrable") but "discourse-new"): see Prince (1992) for an analysis of what she calls "inferrables" in these terms. As Lambrecht \& Lemoine (to appear, 2006) note, null complements bearing this value cannot be replaced by unaccented pronouns, showing their status as somewhat less than "high" accessibility markers.

If we consider the Givenness Hierarchy solely in terms of the scale of cognitive statuses it recognizes, it would seem that the three interpretation types we have isolated for null complements in English range over the following positions: the polar ones for the anaphoric subtype ("in-focus") and the non-referential one ("type identifiable"), with the 'discourse-new' subtype ranging over the three intermediate statuses "familiar" or "uniquely identifiable" (for the 'hearer-old' variant) and "referential" (for the 'brand-new' one):

(21) in focus $>$ activated $>$ familiar $>$ uniquely identifiable $>$ referential $>$ type identifiable (Gundel, Hedberg \& Zacharski, 1993: 275)

In the case of the anaphoric subtype, the implicit argument's "in-focus" status would seem unproblematic; in that of the non-referential one, given that the argument concerned is only an "inherent" one, and as such part of the characterisation of the essential meaning of the host predicate, it is analogous to the lexical component of an indefinite NP introduced by the indefinite article, as specified by the least restrictive cognitive status on the GH, namely "typeidentifiable": the addressee is assumed by the speaker only to have access to the conventional sense of the head noun of an indefinite article $+\mathrm{N}$ sequence, just as in the case of the nonreferential null complement subtype, whose very raison d'être is to highlight the essential semantic content of the predicate whose second argument it represents, qua lexical item. There is a precedent within the GH itself for a given form type to occur at more than one position on the Hierarchy with different semantic-pragmatic values: namely, the proximal demonstrative determiner this, which occurs both under the status "activated" and under that of "referential" (in its referent-introducing use), statuses which are also not adjacent in the Givenness Hierarchy. Thus the cognitive statuses which may be signalled by null complements in English include all but one of the six positions recognized by the GH.

Let us look now at Levinson's (2000) neo-Gricean account in terms of referential "minimization" (zero forms could not be more "minimal" in this respect!). I will mainly be considering the context-bound, anaphoric value of the $\mathrm{A}^{2}$ or $\mathrm{A}^{2}$ and $\mathrm{A}^{3}$ arguments here (i.e. the referential value corresponding to the highest degree of accessibility of the four subtypes). Let us consider a range of examples - some of which have already been presented. 
(22) a "... and the Archers' one-year-old grandson had been playing in the room moments before it hit $\varnothing . "\left(\right.$ ex. $\left.\left(2 c^{\prime \prime}\right)\right)$

b " "...always lock your car and never leave anything valuable inside ø."

(The Radio Times, section on "Crime", $\mathrm{p}$ 114)

c Come on now, break ø! They've all got to go, you know! (ex. (19))

$\mathrm{d} \quad$ [At the theatre: $\mathrm{A}$ is seated next to $\mathrm{B}$, who is placed right behind a tall spectator in the seat in front]

A to B: Can you see $ø$ ?

e "Care and Cleaning

(...) Refer to instructions below ø for cleaning the 'Cookclean' removable side panels (if fitted)..." (Belling cooker installation and user instructions leaflet)

f "Glass Lid (Glass)

(...) Stubborn stains can be removed with a cream, paste or liquid cleaner, or by gently rubbing $\varnothing$ with liberally soaped, very fine steel wool pads...." (Continuation of (22e))

g

“...Polish ø with a clean dry or kitchen roll..." (Continuation of (22f))

The zero complement in (22a) refers to 'the Archers' house', the one in (22b) to 'the reader's car', in (22c) it refers to 'the bowl with an attractive design which the hearer is examining', in (22d), to 'the stage in the theatre in which A and B are seated' (this is an instance of the discourse-new referential subtype), in (22e) to 'the occurrence of the null form in question', in (22f) to 'those stubborn stains which may still be on the glass lid of the cooker', and in $(22 \mathrm{~g})$ to 'the glass lid of the cooker'.

In (22a), as we have seen, the unaccented pronoun it would have been possible, but with a potential shift in reference; in (22b), it would have been possible in place of the zero, with the same referential value; in (22c), it or that would clearly have been possible substitutes for the null complement; in (22d), it would have been odd as a replacement for the zero form; in (22e), it could not have occurred instead of the zero, since this is a textual-deictic use: only the proximal demonstrative pronoun this would have been an appropriate substitute here; in (22f), the plural pronoun them could have replaced the zero, with the same referent; but in $(22 \mathrm{~g})$ them could not have occurred instead of the zero, since the predicative part of the anaphoric clause would have predicated an incoherent state of affairs of its referent 'the stubborn stains which may get stuck to the cooker's glass lid': for the entity retrieved by the pronoun would be something which would hardly be likely to be "polished"! Only the pronoun it would target the intended referent of the zero, namely 'the cooker's glass lid', the topic of this discourse segment.

The host predicators in (22) have the following aspectual properties: hit is an achievement predicate, inside is a state one, break a transition predicate (in its transitive occurrence in (22c), it is a causative-accomplishment predicate), see is a state predicate ${ }^{18}$, below is also a state predicate, $r u b$ is an activity predicate, and polish is likewise an activity predicate (more specifically, an "incremental-object" predicate).

\footnotetext{
${ }^{18}$ Note here that A's question does not bear on the visual capacity of the addressee as such (see is not a pure intransitive predicate here), but pertains to whether or not B has a view of the stage which both interlocutors are facing.
} 
Now, Levinson (2000: 285) proposes what he calls "The general anaphora pattern" whereby zero forms ("NP-gaps") used in positions where overt pronouns could also have been used, are more likely to implicate local coreference in conformity with his "I(nformativity)principle", while pronouns occurring in place of a possible zero will "M(anner)-implicate" non-coreference. In turn, a pronoun used in place of an otherwise possible lexical NP (e.g. a definite NP) will I-implicate coreference, while the reverse pattern will M-implicate noncoreference. The "general anaphora pattern" is given as (26) in chapter 4:

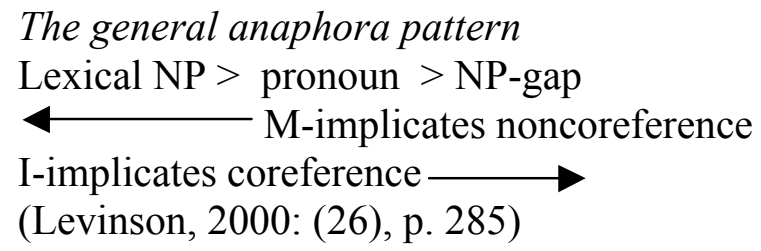

According to the I-principle (Levinson, 2000: (39), pp. 114-115), speakers tend to provide the minimum amount of information needed, consistent with the general direction of the exchange, while their addressees are supposed to infer from each utterance a more specific, more fully informative interpretation. As for the M-principle (Levinson, 2000: (69), pp. 1367 ), this basically says that the use of a marked expression in place of an otherwise possible unmarked one which would have I-implicated the corresponding normal, stereotypical situation, tends to signal the speaker's intention to convey a marked interpretation.

However, in the seven examples of zero complement anaphora or deixis in (22), only (22a) would seem to conform to Levinson's "general anaphora pattern", as far as the second and third positions on the scale are concerned ${ }^{19}$ : for the overt pronoun it, a "marked" form in relation to the possible unmarked zero, would not have had the same referent. However, the way the scale is said to operate in relation to this example is not fully clear here, since it would have had a locally coreferent interpretation (with 'the room in which the Archers' oneyear old grandson had been playing minutes earlier'), the zero complement of hit referring more globally to 'the Archers' house'. In (22b), (22c), (22f) and (22g), the interpretation of tokens of the pronoun it (or them in the case of (22f)) in place of the zero would be the opposite of the prediction from (23): namely, it and the zero would have the same strict anaphoric or "exophoric" interpretation (in (22c)), respectively, maintaining the reference to the reader's car in (22b), to the problematic entity being held up for examination by the addressee (i.e. 'the bowl') in (22c), to the stubborn stains which may remain on the cooker's

\footnotetext{
${ }^{19}$ There are various independent co-textual and contextual factors listed by Huang (2000) and Blackwell (1998: 613-614, item (30)); (2001: 939, item (10d)) which are claimed to neutralise the operation of the M-principle in particular. For example, in (22b), the conjoined parallel imperative construction makes a coreferential interpretation of the zero complement in the second conjunct highly preferred. A similar explanation for the locally coreferent interpretation assigned to the zero in the second disjunct of (22f) would stem from the parallel coordination effected via the connective or: here, the antecedent NP and zero arguments bear the same semantic role (Patient), and the predication in the first disjunct is ellipsed in the second, with the manner by-phrase paralleling the means PP in the antecedent predication. In Blackwell (2001: 939, item (10d)), the author hierarchises the factors favouring a coreferential interpretation for the variety of types of Spanish indexical expressions she studies, placing Levinson's alternations of given expression types in terms of the operation of the I- and Mprinciples (as reflected in (23) for example) at the very end of her scale. This means that in many instances, the resolution of given expression types (in our case, complement zeros and overt inanimate object pronouns) may be determined without recourse to the I- and M-principles at all.
} 
glass lid in (22f), and to the cooker's glass lid in (22g). And in (22d), it would have been odd in place of the zero, so no clear implicature could be drawn.

What seems clear in relation to the possible alternation between zero and it in this respect is this: the zero complements tend to refer more diffusely, more globally than the overt inanimate pronoun, which in several cases would have a more specific interpretation: in (22a) 'the room' would be a more specific referent than 'the house' (of which the room in question is a part). In (22d), while the zero complement refers in a general manner to the ambient scene as a whole (including the décor, the actors, etc.), the overt pronoun would refer more specifically to the stage qua stage. In $(22 \mathrm{~g})$, the zero form would naturally target the current discourse segment's topical referent 'the cooker's glass lid', while the overt plural pronoun them would more naturally pick up a more local topical referent, the one introduced in subject position of the preceding sentence. The singular pronoun $i t$, on the other hand, would refer back to the same discourse-segment topic ('the cooker's lid') as the zero. Notice how the zero in the immediately preceding clause in the continuous text (represented by (22f)) refers to a more local topic ('stubborn stains which may be stuck to the cooker's glass lid'), whereas the zero complement of polish in (22g) (a continuation of the segment reproduced in (22f)) targets, as we have seen, the current local discourse topic ('the cooker's glass lid'). In this case too, the overt pronoun would have a more local referent than the zero. Zero complements appear to be much more flexible than overt pronouns, and are more sensitive to context. It is not evident that Levinson's principles would actually predict these differences.

\section{Conclusion}

The fact that one or more non-first arguments of a transitive predicate are unrealized in the syntax does not mean that it is intransitive (i.e. monovalent) semantically. The constraints on the occurrence of null complements for such verbs in English would appear to be determined by the need to recover (i.e. to "license") that or those non-first argument(s).

In two of the three subtypes (the non-referential one and the anaphoric one), the zero complement of otherwise transitive (or ditransitive) verbs, adjectives or prepositions is licensed by the highly presupposed nature of its content: in the first case, an 'inherent' argument, part of the host predicate's meaning, potentially narrowed to a more specific denotation type by features of the co(n)text; and in the second, a topical (and hence also highly presupposed) discourse referent licensed via the cotext and/or context of utterance of the host predicate, which is retrieved by the null complement. The former subtype is lexically presupposed, while the latter is discourse-pragmatically presupposed. As for the third of the three subtypes of null complement, the referential 'discourse-new' one, its existence is licensed via a combination of the lexical-semantic and Aktionsart structure of the host predicate (making available an appropriate inherent argument, e.g. 'letter' in the case of write iu its "correspond" sense) and certain referentially-relevant features of the host predication as a whole (tense, aspect, temporal or locative 'framing' adverbial modifiers etc.). Only the inherent-argument component of the discourse-new referent evoked is (lexically) presupposed in such a case. Hence, this subtype may be viewed as the marked member of the set of null complement interpretation types.

Zero forms are claimed by linguists such as Givón and Ariel to be extremely high accessibility markers. Indeed, they figure at the extreme "High Accessibility" pole of Ariel's (2001: 31, item (2)) Accessibility Marking Scale, where each referential expression-type is 
assigned a degree of accessibility relative to the status of its intended referent in the addressee's memory, as assumed by the speaker at any given point in a discourse. Zero forms do not figure at all in Gundel, Hedberg \& Zacharski's (1993; 2000) "Givenness Hierarchy", though as Nancy Hedberg (p.c.) points out, in their (1993) article, these authors did include zero NPs on the Givenness Hierarchies which they postulated for Spanish, Chinese, Japanese and Russian, claiming that their referents are of necessity in focus.

In both the non-referential and the referential subtypes, the host predicator's selection restrictions play a role: in the first case, in transferring them to the null complement, where they are then narrowed to a denotation type via the contextual domain of reference of the containing utterance; and in the second, in restricting the zero element's ability to denote a referent (whether contextually salient or not). However, as we have seen, the telicity of the whole predication and the possible existence of a culturally-recognized stereotype may nevertheless license the intended referent and so permit the null form. The discussion in $\$ 5.2$ showed that, in general, "referential" zero complements refer more diffusely, more globally, than their overt object pronoun counterparts.

\section{REFERENCES}

Ariel, M. (2001). Accessibility theory: an overview. Ch. 2 in T. Sanders, J. Schilperoord \& W. Spooren (eds.) Text Representation: Cognitive and linguistic aspects (pp. 29-87). Amsterdam/Philadelphia: John Benjamins.

Berrendonner, A. (1995). Redoublement actanciel et nominalizations. In Problèmes de sémantique et de relations entre micro- et macro-syntaxe. Actes des Rencontres de Linguistique, M-J. Reichler-Béguelin (ed.), 215-244. BENEFRI-Strasbourg, Neuchâtel, 1921 May 1994, SCOLIA 5.

Blackwell, S.E. (1998). Constraints on Spanish NP anaphora: the syntactic versus the pragmatic domain. Hispania 81(3): 606-618.

Blackwell, S.E. (2001). Testing the neo-Gricean pragmatic theory of anaphora: the influence of consistency constraints on interpretations of coreference in Spanish. Journal of Pragmatics 33: $901-941$.

Brisson, C. (1994). The licensing of unexpressed objects in English verbs. In K. Beals, J. Denton, R. Knippen, L. Melnar, H. Suzuki \& E. Zeinfeld (eds.), Papers from the $30^{\text {th }}$ Regional Meeting of the Chicago Linguistic Society Vol. 1: The Main Session, Chicago: CLS, 90-102.

Butt, M. \& Geuder, W. (eds.) (1998). The Projection of Arguments. Lexical and compositional factors. Stanford: CSLI Publications.

Cornish, F. (1999). Anaphora, Discourse, and Understanding. Evidence from English and French. Oxford: Clarendon Press (Oxford University Press).

Cornish, F. (2002). 'Downstream' effects on the predicate in Functional Grammar clause derivations. Journal of Linguistics 38(2): 247-278.

Cornish, F. (2005). Degrees of indirectness: two types of implicit referents and their retrieval via unaccented pronouns. In A. Branco, T. McEnery \& R. Mitkov (eds.), Anaphora Processing: Linguistic, Cognitive and Computational Modelling. Amsterdam \& Philadelphia: John Benjamins, Current Issues in Linguistic Theory, vol. 263, 199-220. 
Cornish, F., Garnham, A., Cowles, W., Fossard, M. \& André, V. (2005). Indirect anaphora in English and French: a cross-linguistic study of pronoun resolution. Journal of Memory and Language 52(3): 363-376.

Dik, S.C. (1997). The Theory of Functional Grammar, Part 1: The structure of the clause. Berlin/New York: Mouton-de Gruyter.

Fillmore, C.J. (1986). Pragmatically-controlled zero anaphora. In K. Nikiforidou et al. (eds.), Proceedings of the $12^{\text {th }}$ Annual Meeting of the Berkeley Linguistics Society, Berkeley, BLS: 95-107.

García Velasco, D. \& Portero Muñoz, C. (2002). Understood objects in Functional Grammar. Working Papers in Functional Grammar n ${ }^{\circ}$ 76: 1-22.

Goldberg, A. (2001). Patient arguments of causative verbs can be omitted: the role of information structure in argument distribution. Language Sciences 23: 503-524.

Groefsema, M. (1995). Understood arguments: a semantic/pragmatic approach. Lingua 96: 139-161.

Gundel, J.K., Hedberg, N. \& Zacharski, R. (1993). Cognitive status and the form of referring expressions in discourse. Language 69(2): 274-307.

Gundel, J.K., Hedberg, N. \& Zacharski, R. (2000). Statut cognitif et forme des anaphoriques indirects. Verbum XXII, 1: 79-102.

Huang, Y. (2000). Anaphora. A cross-linguistic study. Oxford: Oxford University Press.

Jackendoff, R.S. (1990). Semantic Structures. Cambridge, Mass.: MIT Press.

Jackendoff, R. (2002). Foundations of Language. Brain, meaning, grammar, evolution. Oxford: Oxford University Press.

Kleiber, G. (1994). Anaphores et pronoms. Brussels: Duculot.

Koenig, J-P. \& Mauner, G. (2000). A-definites and the discourse status of implicit arguments. Journal of Semantics 16: 207-236.

Lambrecht, K. \& Lemoine, K. (to appear, 2006). Definite null objects in (spoken) French. A Construction-Grammar account. To appear in M. Fried \& H. Boas (eds.), Proceedings of the First International Construction-Grammar Conference. Amsterdam/Philadelphia:John Benjamins.

Larjavaara, M. (2000). Présence ou absence de l'objet. Limites du possible en français contemporain. Helsinki: Academia Scientiarum Fennica.

Lehrer, A. (1970). Verbs and deletable objects. Lingua 25: 227-253.

Levin, B. \& Rappaport Hovav, M. (2005). Argument Realization. Cambridge: Cambridge University Press.

Levinson, S.C. (2000). Presumptive Meanings. The theory of Generalized Conversational Implicature. Cambridge, MA/London, England: MIT Press.

Mairal Usón, R. \& Faber, P. (2002). Functional Grammar and lexical templates. In Mairal Usón \& Pérez Quintero (eds.), 39-94.

Mauner, G., Melinger, A., Koenig, J-P. \& Bienvenue, B. (2002). When is participant information encoded? Evidence from eye-monitoring. Journal of Memory and Language 47: 386-406.

Mejri, S. \& François, J. (to appear, 2005). Restrictions sémantiques sur l'objet sous-entendu de verbes transitifs (le cas de boire). To appear in J. François \& S. Mejri (eds.) Composition syntaxique et figement lexical. Caen: Presses Universitaires de Caen (Bibliothèque de Syntaxe \& Sémantique, volume 3). 
Mittwoch, A. (1982). On the difference between eating and eating something: activities versus accomplishments. Linguistic Inquiry 13(1): 113-122.

Noailly, M. (1998a). Transitivité absolue et type de prédication. In M. Forsgren, K. Jonasson \& H. Kronning (eds.), Prédication, assertion, information. Actes du Colloque d'Uppsala en linguistique française, 6-9 June 1996. Stockholm: Gotab, 377-384.

Noailly, M. (1998b). Emploi absolu, anaphore zéro et transitivité. In A. Rousseau (ed.), La Transitivité. Lille: Éditions du Septentrion, 131-144.

Prince, E.F. (199). The ZPG letter: Subjects, definiteness and information status. In Discourse descriptions: Diverse analyses of a fund-raising text. S. Thompson \& W. Mann (eds.), 295325. Philadelphia/Amsterdam: John Benjamins.

Pustejovsky, J. (1995). The Generative Lexicon. Cambridge, Mass.: MIT Press.

Rappaport Hovav, M. \& Levin, B. (1998). Building verb meanings. Ch. 4 in Butt \& Geuder (eds.), 97-134.

Ritter, E. \& Thomas Rosen, S. (1998). Delimiting events in syntax. Ch. 5 in Butt \& Geuder (eds.), 135-164.

Van Hout, A. (1999). Event semantics in the lexicon-syntax interface: verb frame alternations in Dutch and their acquisition. In C. Tenny \& J. Pustejovsky (eds.) Events as Grammatical Objects. The Converging Perspectives of Lexical Semantics and Syntax. Leland Stanford Junior University: CSLI Publications, 230-282.

Van Valin, R.D. \& LaPolla, R.J. (1997). Syntax: Structure, meaning and function. Cambridge: Cambridge University Press.

Vendler, Z. (1967). Linguistics in Philosophy. Ithaca, New York: Cornell University Press. 